\title{
A experiência do sujeito em Dispersão, de Mário de Sá-Carneiro
}

\author{
Bernardo Nascimento de Amorim \\ Universidade Federal de Minas Gerais
}

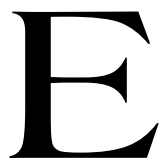

m um texto bastante conhecido no mundo acadêmico, publicado originalmente em Hamburgo, na Alemanha, em 1956, Hugo Friedrich aponta como uma das características da lírica moderna uma pretendida e significativa separação entre o sujeito da lírica e a pessoa empírica do poeta. Tratar-se-ia de uma separação entre a lírica e o coração, em direção oposta ao que pretendiam os românticos, para quem importaria, antes de tudo, na poesia, a expressão de paixões pessoais. A impessoalidade, a "capacidade de neutralizar o coração pessoal", ${ }^{1}$ seria uma das marcas mais relevantes da poesia moderna. Segundo Friedrich, exemplar, neste sentido, entre outros, seria o caso de Rimbaud, em cuja obra haveria uma "separação anormal entre o sujeito poético e o eu empírico", 2 tornando-se o eu uma "multiplicidade dissonante de vozes". ${ }^{3}$ O autor chama a atenção sobre a questão do que denomina despersonalização. Não por mera coincidência, o termo também é usado em um conhecido ensaio de T. S. Eliot, intitulado "Tradição e talento individual", no qual o poeta-crítico procura definir um "processo de despersonalização", 4 afirmando que "a evolução de um artista é um contínuo auto-sacrifício, uma contínua extinção da personalidade". 5 Para Eliot, na poesia, o poeta não expressaria a sua

\footnotetext{
${ }^{1}$ FRIEDRICH, 1991, p. 37.

${ }^{2}$ FRIEDRICH, 1991, p. 69.

${ }^{3}$ FRIEDRICH, 1991, p. 69.

${ }^{4}$ ELIOT, 1989, p. 42.

${ }^{5}$ ELIOT, 1989, p. 42.
} 
personalidade, pois o artista seria aquele que promove em si mesmo uma distinção entre o homem que experimenta suas paixões e sentimentos e a mente que cria.

Entre os poetas do primeiro modernismo português, dois são os que têm merecido o maior destaque. O primeiro deles é, obviamente, Fernando Pessoa, cuja vasta e complexa obra instiga estudiosos em toda parte. O segundo é Mário de Sá-Carneiro, amigo de Pessoa, seu parceiro na revista Orpheu, poeta e prosador morto precocemente pouco antes de completar vinte e seis anos de idade, quando comete suicídio. Entre os dois autores, relevantes pontos em comum podem ser observados. $\mathrm{Na}$ tentativa de renovar a poesia portuguesa, atentos às correntes estéticas contemporâneas, ambos criaram obras nas quais se percebem traços que remetem a uma certa estrutura da lírica moderna, estrutura própria de uma linhagem que teria em Baudelaire, Rimbaud, Mallarmé, Ezra Pound e T. S. Eliot, entre outros, alguns de seus mais notórios expoentes.

Em 1914, Sá-Carneiro publica dois volumes, um romance, $A$ confissão de Lúcio, e um livro de poemas, Dispersão. Antes, circulava já em Portugal uma pequena edição de textos em prosa seus, de nome Princípio. Durante o período de composição dos poemas, o poeta esteve uma temporada em Paris, seguindo o seu anseio cosmopolita de conhecer a Europa, e de, quem sabe, conquistá-la com sua obra. Os poemas de Dispersão, uma dúzia deles, foram escritos de fevereiro a maio de 1913, momento em que as constantes cartas trocadas com Fernando Pessoa fizeram com que este acompanhasse de perto a gênese da produção de seu amigo e de suas concepções estéticas. Material dos mais interessantes, as cartas de Sá-Carneiro a Pessoa fornecem ao leitor de sua obra uma espécie de arte poética, uma vez que ali se observam muitos dos princípios artísticos que orientavam seu trabalho. A correspondência também permite que se vislumbre algo dos projetos de Fernando Pessoa, em particular quando da criação de seus heterônimos. Não devem passar em branco ao leitor atento trechos como o do comentário sobre a poesia de Ricardo Reis, que, para o autor de A confissão de Lúcio, ao contrário dos poemas de Alberto Caeiro, em que "ainda ressumava de vez em quando Mestre Fernando Pessoa", ${ }^{6}$ seria uma "maravilha de impessoalidade".

\footnotetext{
${ }^{6}$ SÁ-CARNEIRO, 1995, p. 812.

7 SÁ-CARNEIRO, 1995, p. 812.
} 
O que pretendo, aqui, é, utilizando algumas das cartas escritas de Sá-Carneiro para Pessoa entre 1912 e 1914, idéias de Hugo Friedrich sobre a despersonalização e sobre a obra de Rimbaud, o citado ensaio de T. S. Eliot e uma visão geral sobre os poemas de Dispersão, com particular destaque para o primeiro poema do conjunto, procurar pensar a obra do poeta português, relacionando-a, ainda que brevemente, a algumas das tendências da lírica moderna, em especial no que diz respeito ao jogo entre pessoa empírica e sujeito lírico, entre unidade e multiplicidade de vozes no discurso e na experiência poética.

\section{II}

O poema com que se abre Dispersão intitula-se "Partida". Em uma primeira versão, com vinte e seis quartetos, seu nome era "Simplesmente". Menor, mais concentrado, com quatorze estrofes, o texto encontraria a sua forma definitiva. Na seqüência, tem-se o poema "Escavação", título bastante representativo de um movimento que leva o sujeito a buscar a si mesmo, em si mesmo, escavando em procura de algo que parece ter-se perdido. Outros poemas têm também nomes que sugerem a singularidade deste universo poético, fornecendo algo dos seus contornos. São títulos como "Vontade de dormir", "Estátua falsa", "Quase", "Como eu não possuo", "A queda" e o poema que dá nome ao livro, o maior entre os do conjunto. A ligar todos os textos, apresenta-se a figura do poeta, imaginado como uma espécie de ser de exceção, em exílio no mundo das pessoas comuns, ${ }^{8}$ um ser que, evanescente, não se reconhece como algo palpável, concreto, inteiro. A arte configura-se como um meio de ascensão, de elevação a um outro patamar de experienciação da realidade, mas ascensão difícil e efêmera, pois que limitada por uma queda sempre iminente. Muitas vezes, o que se manifesta é a vontade de escapar do sofrimento que a condição do artista impõe. Em outras, ressalta o desejo de retorno a um estado de cessação do movimento, de permanência e

\footnotetext{
${ }^{8}$ O espírito aristocrático de Sá-Carneiro fica evidente em suas cartas a Fernando Pessoa, nas quais se refere a funcionários do correio, entre outros, como subgentes. Também seu desprezo pelos burgueses é notório. A estes, que seriam criaturas "sem complicações psicológicas" (SÁ-CARNEIRO, 1995, p. 827), o escritor chamava de lepidópteros.
} 
unidade. Para iniciar uma maior aproximação do universo lírico de SáCarneiro, em Dispersão, julgo ser interessante propor uma observação de mais perto do poema que abre o livro. Transcrevo-o conforme a edição brasileira da obra completa do escritor, publicada pela Editora Nova Aguilar, em 1995:

\section{Partida}

Ao ver escoar-se a vida humanamente

Em suas águas certas, eu hesito, E detenho-me às vezes na torrente

Das coisas geniais em que medito.

Afronta-me um desejo de fugir

Ao mistério que é meu e me seduz.

Mas logo me triunfo. A sua luz

Não há muitos que a saibam refletir.

A minha alma nostálgica de além, Cheia de orgulho, ensombra-se entretanto, Aos meus olhos ungidos sobe um pranto Que tenho a força de sumir também.

Porque eu reajo. A vida, a natureza, Que são para o artista? Coisa alguma. O que devemos é saltar na bruma, Correr no azul à busca da beleza.

É subir, é subir além dos céus

Que as nossas almas só acumularam, E prostrados rezar, em sonho, ao Deus Que as nossas mãos de auréola lá douraram.

É partir sem temor contra a montanha Cingidos de quimera e de irreal; Brandir a espada fulva e medieval, A cada hora acastelando em Espanha.

É suscitar cores endoidecidas, Ser garra imperial enclavinhada, E numa extrema-unção de alma ampliada, Viajar outros sentidos, outras vidas. 
Ser coluna de fumo, astro perdido, Forçar os turbilhões aladamente, Ser ramo de palmeira, água nascente E arco de ouro e chama distendido...

Asa longínqua a sacudir loucura, Nuvem precoce de sutil vapor, Ânsia revolta de mistério e olor, Sombra, vertigem, ascensão - Altura!

E eu dou-me todo neste fim de tarde À espira aérea que me eleva aos cumes. Doido de esfinges o horizonte arde, Mas fico ileso entre clarões e gumes!...

Miragem roxa de nimbado encanto Sinto os meus olhos a volver-se em espaço! Alastro, venço, chego e ultrapasso; Sou labirinto, sou licorne e acanto.

Sei a Distância, compreendo o Ar; Sou chuva de ouro e sou espasmo de luz; Sou taça de cristal lançada ao mar, Diadema e timbre, elmo real e cruz...

O bando das quimeras longe assoma...

Que apoteose imensa pelos céus!

A cor já não é cor - é som e aroma!

Vêm-me saudades de ter sido Deus...

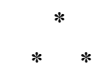

Ao triunfo maior, avante pois!

O meu destino é outro - é alto e é raro.

Unicamente custa muito caro:

A tristeza de nunca sermos dois...?

9 SÁ-CARNEIRO, 1995, p. 55-56. 
Nas quatro primeiras estrofes do poema, observa-se uma oposição e um conflito, cuja relação é complementar. A oposição dá-se entre o poeta, que medita em coisas geniais, incertas, e o mundo exterior, lugar em que se escoam, "humanamente", as "águas certas" da vida. O conflito tem lugar no interior do sujeito, que, diante da sedução de um mistério, seu, manifesta o desejo de fuga. Colocadas as coisas dessa maneira, configura-se um sujeito partido, que oscila, mas que tem a sensação de triunfo, sobre si mesmo, quando vai ao encontro de seu mistério. Temse um conflito dado num plano interiorizado, um conflito, por assim dizer, subjetivo, em que o mundo objetivo tende a desaparecer, recusado por seu baixo teor poético, seu escasso potencial de iluminação. Na terceira estrofe, significativamente, o sujeito é expresso como sendo dotado de uma alma, que se manifesta nostálgica de um espaço de fora do mundo concreto. O vocábulo alma não entra aqui sem maiores conseqüências. Ao que parece, tem-se uma referência a uma espécie de unidade, a uma forma unificante, a que se podem relacionar as idéias de personalidade, individualidade, intimidade pessoal. Nesta estrofe, tanto a oposição quanto o conflito marcam a sua presença, pois esta alma, orgulhosa, antes iluminada, tendendo a elevar-se, a evadir-se do mundo objetivo, indo ao encontro de seu mistério, agora se ensombra, como que retornando à terra, às "águas certas" da vida. Experimenta-se dor, expressa no pranto, o qual, entretanto, é contido. Na estrofe seguinte, tem continuidade a oposição entre a vida e a experiência do artista. Manifestase a reação do poeta à dimensão mais corriqueiramente humana do mundo, recuperando o sentido da estrofe anterior, em que se assumira uma postura de recusa diante do pranto, uma simples efusão, expressão direta, talvez mundana demais, de paixões pessoais. $\mathrm{O}$ artista, aquele que tem os olhos ungidos, reage, fazendo sumir o pranto. A vida e a natureza não têm, aqui, qualquer importância. O puro sentimento não seria aquilo com o que se fabrica a obra de arte.

A partir do terceiro verso da quarta estrofe, o movimento do texto sofre uma alteração, quando tem início a enumeração do que deve fazer e ser o poeta, o artista. A voz do poema, que aqui tenho chamado de sujeito, identifica-se a uma coletividade, ao grupo dos artistas, dizendo o que é o seu dever: "saltar na bruma", "correr no azul à busca da beleza", "subir além dos céus", "suscitar cores endoidecidas", "viajar outros sentidos, outras vidas". O desejo, associado ao destino do artista, não seria outro senão o de ascensão, a implicar o risco que só corre aquele que perde o 
temor e ousa, aquele que escapa do cotidiano em busca de um mistério, criando sentidos que o comum dos homens, presos a uma lógica limitadora, não pode reconhecer. $\mathrm{O}$ artista teria um compromisso com a beleza, um compromisso ligado a uma vocação, que determina uma missão, sagrada, próxima da missão religiosa. O poeta deve rezar, "em sonho", a um Deus que as suas próprias mãos fabricariam, dando-lhe o brilho do ouro. "Sonho", "quimera" e "irreal" envolvem o artista, pois o seu espaço não é o da vida comum, o do mundo real, sempre pouco para quem anseia outras vidas, mais belas, mais ricas, mais iluminadas. O fazer artístico seria como que uma batalha, o artista, um legítimo cavaleiro em busca de um ideal, a brandir uma espada dourada. A arte configura-se como uma ampliação da alma. O artista aparece como aquele que recebe uma "extrema-unção", aquele que é ungido, sagrado, investido de uma autoridade específica, mas que, ao mesmo tempo, pode ser também um enfermo, que sofre por sua vocação, tendo que se manter isolado dos homens.

Nas estrofes oito e nove, o movimento do texto continua na mesma direção, mas há uma relevante mudança no caráter das enumerações. Agora, o sujeito parece mesmo ampliar-se, identificando-se a elementos de natureza diversa. Há uma espécie de transmutação, em que o sujeito transforma-se em "coluna de fumo", "astro perdido", "ramo de palmeira", "água nascente", "arco de ouro e chama distendido", "asa longínqua a sacudir loucura", "nuvem precoce de sutil vapor", "ânsia revolta de mistério e olor" e, por fim, em "sombra", "vertigem", "ascensão", "altura". As palavras trazem desde imagens de coisas vagas, evanescentes, como a coluna de fumo e a nuvem de sutil vapor, de coisas distantes, como o astro perdido e a asa longínqua, de elementos da natureza, como o ramo de palmeira e a água nascente, até uma imagem que remete ao brilho e à riqueza, com o arco de ouro e chama. O final da enumeração, o último verso da seqüência, concentrado em quatro palavras, dá uma idéia do que experimenta o artista em seu "viajar outros sentidos", em seu caminho de ascensão rumo ao mistério, caminho que, começando com a sombra e passando pela vertigem, a loucura, leva, por fim, ao alto.

No décimo quarteto do poema, há uma pequena interferência na lógica mais geral do texto, quando o poeta localiza a sua experiência em um tempo determinado. Trata-se de um "fim de tarde". Não se sabe qual, nem onde, mas, de todo modo, tem-se uma referência temporal que remete a algo do mundo concreto, o mundo que se compartilha com os homens comuns. A referência, entretanto, não altera o caráter da 
experiência, pois o que ressalta é a entrega do artista ao seu movimento de subida, de elevação. Mesmo este fim de tarde é associado ao arder de um horizonte "doido de esfinges". Na estrofe seguinte, dá-se a chegada do poeta ao alto, a sua vitória, que não pode deixar de se relacionar a uma expansão e a uma transmutação. O sujeito se alastra, ultrapassa, multiplica-se, sendo, a um só tempo, elementos díspares como o "labirinto", o "licorne" e o "acanto". Na seqüência, que representa o fim de uma parte do poema, pois antecede duas linhas contínuas de reticências, procedimento gráfico muito usado por Sá-Carneiro, tem-se uma referência a uma espécie muito singular de saber, a que a experiência de elevação e de transmutação daria acesso. O poeta, transfigurado em "chuva de ouro", "espasmo de luz", "taça de cristal", "diadema e timbre", "elmo real e cruz", sabe a "Distância", compreende o "Ar". Depois das reticências, surge uma estrofe, de certo modo, isolada, em que se destaca a imagem de uma apoteose de quimeras nos céus, ao longe, associada a uma transformação sinestésica da cor em som e aroma. A mistura dos sentidos, que não deixa de ser uma espécie de desregramento, viria acompanhada do esplendor dos objetos fabricados pela imaginação, pela fantasia criadora. No último verso do quarteto, o poeta faz uma referência a Deus, que figuraria, aqui, como o demiurgo, um criador de universos, artífice como o poeta. O artista quer assemelhar-se a este Deus. Entretanto, neste ponto, nesta parte isolada do poema, depois do clímax do movimento de ascensão e ampliação, é importante notar que parece haver um certo distanciamento, espacial ("longe") e temporal ("saudades"), sugestivo de uma separação entre a apoteose, a glorificação, e o próprio poeta. Este último não chegaria a experimentar o esplendor, vendo-o de longe, com saudades de sua própria experiência criadora, ou, ainda, para usar os termos de uma outra passagem do texto, que aqui parecem apropriados, com a "alma nostálgica de além".

Por fim, depois dos asteriscos em formato de triângulo, outro sinal gráfico de que lança mão Sá-Carneiro para indicar maiores pausas e intervalos no texto, aparece uma estrofe dividida em duas partes. Primeiro, tem-se a incitação ao triunfo, à vitória, que é a elevação, a ascensão, condição para a criação, destino do poeta, "alto e raro". Depois, dois versos que poderiam colocar talvez um relevante problema para a interpretação do poema. A experiência poética causa uma tristeza, que, expressa como no último verso, é a tristeza de o poeta nunca chegar a ser dois. Caberiam, então, aqui, duas leituras, ao menos. A tristeza poderia 
ser decorrente do possível malogro do movimento de multiplicação do sujeito, de sua ampliação. Triste seria o poeta por não chegar ao lugar que almeja, por ter o seu movimento de ascensão e dispersão falhado. Por outro lado, aquela poderia ser a tristeza de nunca se poder compartilhar com um outro a experiência, a tristeza do poeta por estar fadado ao isolamento, ao alheamento da simplicidade de uma vida comum, sem vertigem, loucura e quimeras. Se a primeira leitura fosse privilegiada, dever-se-ia reforçar a idéia de que o desejo mais íntimo do poeta é mesmo o da multiplicação de si mesmo, o de um firme desregramento. No entanto, ao autorizar a segunda leitura, apresenta-se não só a primeira versão do poema, "Simplesmente", ${ }^{10}$ mas a voz do próprio Sá-Carneiro, que diz, em carta a Fernando Pessoa, de fevereiro de 1913: "Não cultivar a arte diária é fulvamente radioso e grande e belo; mas custa uma coisa semelhante ao que custa não viver a vida diária: A tristeza de nunca sermos dois". ${ }^{11}$

\section{III}

Terminado o movimento de análise, é chegado o momento de procurar apontar algumas relações, propositalmente pontuais, entre a poética de Sá-Carneiro, vislumbrada, sobretudo, em Partida, e outras referências, aproveitando algo do que a perspectiva comparatista pode oferecer. É neste ponto que creio ser proveitoso pensar em Rimbaud, em particular, tal como visto por Hugo Friedrich, em seu Estrutura da lírica moderna. Ali, o autor define a poética do precoce poeta, apropriadamente, ao que me parece, como ligada a uma necessidade de evasão do mundo real, a um desejo de se chegar ao desconhecido, de perseguir um mistério, num movimento de ampliação dos sentidos, de radical desregramento. Rimbaud teria cumprido um projeto de desordenação de todos os sentidos, em especial nos poemas em prosa de Une saison en enfer Illuminations, que o levariam a tornar-se, conforme o seu anseio, o "grande enfermo,

\footnotetext{
${ }^{10}$ Neste poema, há toda uma primeira parte dedicada a uma passante, que representa a simplicidade da vida. Destaco a quinta estrofe da composição, em que se faz uma comparação entre o poeta e a mulher: "(Ah, como nesse instante a invejei, / Olhando a minha vida deplorável - / A ela, que era enérgica e prestável. / Eu, que até hoje nunca trabalhei!...)" SÁ-CARNEIRO, 1995, p. 243. ${ }^{11}$ SÁ-CARNEIRO, 1995, p. 748-749.
} 
o grande delinqüente, o grande proscrito e o sumo sábio". ${ }^{12}$ No autor de Dispersão, percebe-se, como em Rimbaud, a mesma necessidade de evasão, de fuga da realidade, assim como o movimento de ampliação. Entretanto, e é isso que me interessa ressaltar, diferentemente do que aconteceria com o poeta francês, tal movimento, como se vê em "Partida", dá-se no seio de um conflito explicitado entre aquela necessidade e uma força como que gravitacional a puxar o poeta para o mundo comum. Haveria, no autor português, uma tensão entre, de um lado, a vontade de ascensão, de ampliação, e, de outro, um certo temor da experiência do desregramento ou uma certa consciência melancólica da precariedade de tal experiência. Embora o poeta reconheça a grandeza e o caráter extraordinário do movimento de elevação, de criação de um outro universo, com outras possibilidades de subjetivação, de acesso a um saber de outra ordem, o fato é que ele também manifesta um desejo de fuga do seu mistério, uma hesitação e um receio de que não consiga alcançar a sua meta. Como se nota em versos como os de "Além-tédio", muitas vezes se destaca o caráter efêmero da experiência de ampliação: "Parti. Mas logo regressei à dor, / Pois tudo me ruiu... Tudo era igual: / A quimera, cingida, era real [...]" ${ }^{13}$ Em "A queda", o que se vê é a dúvida quanto à verdade do que é vivenciado: "Se acaso em minhas mãos fica um pedaço de ouro, / Volve-se logo falso... ao longe o arremesso...". ${ }^{14}$ Em "Como eu não possuo", o poeta, manifestando a sua impotência, fica a meio caminho, entre dois espaços: "Falta-me egoísmo pra ascender ao céu / Falta-me unção pra me afundar no lodo". ${ }^{15}$ O mesmo parece ser encenado em "Quase": "Eu falhei-me entre os mais, falhei em mim, / Asa que se lançou mas não voou...". ${ }^{16}$ Diferentemente de Rimbaud, SáCarneiro se mostra hesitante, melancólico, saudoso, como que se sentindo incapaz de cumprir o destino para o qual teria sido feito.

Outro ponto relevante, ainda no que tange às comparações, seria aquele que diz respeito à questão da despersonalização, marca da lírica moderna, segundo Friedrich, alcançada, de diferentes modos, em

\footnotetext{
${ }^{12}$ RIMBAUD apud FRIEDRICH, 1991, p. 63.

${ }^{13}$ SÁ-CARNEIRO, 1995, p. 69.

${ }^{14}$ SÁ-CARNEIRO, 1995, p. 72.

${ }^{15}$ SÁ-CARNEIRO, 1995, p. 67.

${ }^{16}$ SÁ-CARNEIRO, 1995, p. 65.
} 
Baudelaire, Mallarmé e Rimbaud. Em particular, neste último, o percurso da ampliação seria trilhado em um texto desprovido de um eu configurado como uma unidade reconhecível, passível de uma relação de referencialidade com a figura do autor. Tratar-se-ia de um processo que levaria à transformação do sujeito lírico em um objeto fragmentado em diversas vozes, sem origem determinável, como se vê, de modo muito claro, em Illuminations. Desse modo, cumprir-se-ia a completa despersonalização do poema, cuja subjetividade se dissolve nas vozes indeterminadas do texto. Novamente, aqui, em sentido contrário ao que acontece com o poeta francês, em Sá-Carneiro, especialmente em Dispersão, parece ser possível, ainda, imaginar a permanência de uma idéia de unidade, seja na repetida referência à existência de uma alma, que seria uma unidade metafísica substancial, seja na ligação ainda possível entre a personalidade do artista e o sujeito que, nos poemas, dá-se a conhecer. Significativamente, o próprio Sá-Carneiro é quem afirma, num ponto de carta sua a Fernando Pessoa, que "vida e arte, no artista, confundem-se, indistinguem-se", ${ }^{17} \mathrm{e}$ quem diz, na mesma carta: "Há versos que me agradam muito, porque me encontro neles". ${ }^{18}$ Em comentário sobre o poema Dispersão, em pleno processo de composição, o poeta confessaria, ainda, a Pessoa: "Depois de composta a poesia, vi que ela era sincera, que encerra talvez um canto do meu estado de alma". ${ }^{19}$ Neste sentido, a lírica de Sá-Carneiro, embora promovesse um certo afastamento do sentimentalismo pessoal, da efusão notadamente muito cara aos românticos, não agenciaria uma completa neutralização da pessoa do artista, não seguindo efetivamente a trilha de um completo "autodespojo do eu", ${ }^{20}$ o caminho da "desumanização do sujeito lírico". ${ }^{21}$ Haveria, certamente, na obra do autor de "Partida", um alinhamento aos poetas da modernidade, em particular nas questões que sua poesia coloca em pauta e na importância que em sua obra assume a idéia de artifício, de fantasia criativa, a deslocar o valor da confissão de paixões pessoais, o que o aproximaria de Baudelaire, de Rimbaud, de T. S. Eliot. Ao que parece, entretanto, nesta poética, a personalidade nunca

\footnotetext{
${ }^{17}$ SÁ-CARNEIRO, 1995, p. 748.

${ }^{18}$ SÁ-CARNEIRO, 1995, p. 749.

${ }^{19}$ SÁ-CARNEIRO, 1995, p. 773.

${ }^{20}$ FRIEDRICH, 1991, p. 63.

${ }^{21}$ FRIEDRICH, 1991, p. 37.
} 
seria de todo extinta, sacrificada, como queria o autor de The waste land, pois algo de uma unidade, em meio à dispersão, permanece sendo buscado como referência. Lembre-se, a este respeito, a primeira estrofe de "Escavação", em que o anseio do poeta parece ser justamente o de encontrar algo como uma intimidade pessoal, fixa em meio ao que se transforma: "Numa ânsia de ter alguma coisa, / Divago por mim mesmo a procurar, / Desço-me todo, em vão, sem nada achar, / E minha alma perdida não repousa." 22

\section{IV}

A palavra dispersão pode significar, entre outras coisas, ato ou efeito de espalhar, dissipar, desfazer, fazer ir para diferentes partes. Em "Dispersão", de Sá-Carneiro, observa-se, como em "Partida", uma associação entre a arte, a criação, e um movimento de ascensão, relacionado à transmutação do sujeito, à sua expansão. Por um lado, este movimento adquire um sinal positivo, uma vez que a dissipação identifica-se à elevação, modo de contato com um saber de ordem superior, inacessível à maioria dos homens. Por outro, entretanto, prevalece um sinal negativo, quando, perdido o caráter de processo do movimento de transmutação, tem lugar a expressão de um sentimento melancólico de desintegração, na voz de um sujeito que se desconhece, não consegue fixar-se, não se encontra, sendo como que um objeto perdido. É o que dizem os versos de "Como eu não possuo": "Quero sentir. Não sei... perco-me todo... / Não posso afeiçoar-me nem ser eu [...]". ${ }^{23}$ Neste segundo caso, a desintegração, a fragmentação, não seriam configuradas como parte de um processo desejado, mas, antes, como manifestações associadas a um sentimento de perda, que derivaria da permanência de uma idéia de unidade, da idéia subjacente de que o sujeito existe em algum lugar, embora, muito provavelmente, em um lugar inacessível. Em Escavação, tem-se a pergunta, que parece insistir: “- Onde existo que não existo em mim?". ${ }^{24}$ Nos doze poemas de Dispersão, imagino poder afirmar que não haveria, verdadeiramente, um despojamento da construção de uma identidade da

\footnotetext{
${ }^{22}$ SÁ-CARNEIRO, 1995, p. 57.

${ }^{23}$ SÁ-CARNEIRO, 1995, p. 67.

${ }^{24}$ SÁ-CARNEIRO, 1995, p. 57.
} 
voz poética, que poderia ser referenciada a uma personalidade, ainda que não exatamente idêntica à personalidade do artista. Não parece ter lugar, no livro, efetivamente, aquela referida multiplicidade dissonante de vozes, que viria a jogar por terra a idéia de sujeito enquanto unidade. A experiência que se daria a conhecer, nos textos do poeta português, seria mais propriamente a experiência de um único sujeito, que se imagina disperso, mas que não deixa de desejar o encontro consigo mesmo, supondo que exista, de algum modo, em algum tempo e em algum lugar, uma entidade una e indivisível, representativa do sujeito.

Significativamente, ainda, poder-se-ia conjeturar que a idéia de unidade faz-se presente também quando se pensa Dispersão, o livro, como o resultado de um projeto de ordenação. O último poema do conjunto começa com os dois versos: "E eu que sou o rei de toda essa incoerência, / Eu próprio turbilhão, anseio por fixá-la”. ${ }^{25}$ A suposta incoerência da obra teria como referencial o próprio sujeito, um mesmo sujeito, que, tentando fixá-la, tenta também ordenar o turbilhão de uma experiência de dispersão. Ter-se-ia uma vontade de ordenação, de edificação, que contrasta com a dissipação em alguns momentos desejada nos textos, dissipação esta associada à ascensão a uma outra esfera de experiência e conhecimento. O jogo, aqui, consistiria mesmo na tentativa de dar forma ao disperso, ainda que esta seja uma forma que preserve a dispersão, pois talvez seja ela a marca maior da experiência subjetiva. Em linhas gerais, seria este um dos movimentos marcantes da poesia de SáCarneiro, movimento que parece manter esta poesia em um ponto específico no caminho da lírica moderna, além da simples confiança satisfeita na unidade do sujeito, sim, mas aquém de uma experiência mais radical de dissipação. Ter percebido este lugar, esta singularidade do autor de Dispersão, creio que, por ora, terá valido a pena.

\section{Referências}

BERQUÓ, Franca. A melancolia narcísica na lírica de Sá-Carneiro. In: Semana de Estudos Mário de Sá-Carneiro. Anais. Belo Horizonte: Centro de Estudos Portugueses, FALE/UFMG, 1994. p. 157-168.

${ }^{25}$ SÁ-CARNEIRO, 1995, p. 72. 
ELIOT, T. S.. Tradição e talento individual. In: Ensaios. São Paulo: Art Editora, 1989. p. 37-48.

FRIEDRICH, Hugo. Estrutura da lírica moderna: da metade do século XIX a meados do século XX. 2 ed. São Paulo: Duas Cidades, 1991. 349 p. (Problemas atuais e suas fontes, 3).

MOISÉS, Massaud. Modernismo. In: . A literatura portuguesa. $32^{\mathrm{a}}$ ed. São Paulo: Cultrix, 2003. p. 235-309.

RIMBAUD, Arthur. Poésies. Une saison en enfer. Illuminations. Paris: Gallimard, 2002.

SÁ-CARNEIRO, Mário de. Obra completa. Rio de Janeiro: Nova Aguilar, 1995.

SIMÕES, João Gaspar. [Estudo crítico]. In: Sá-Carneiro, Mário de. Obras completas de Mário de Sá-Carneiro. Lisboa: Ática, 1973. p. 11-47. v. 2.

\section{Resumo}

Os doze poemas de Dispersão, de Mário de Sá-Carneiro, apresentam uma poética em que o sujeito é o núcleo de todo o discurso, um sujeito que se lança numa tentativa de expansão que lembra o desejo de Rimbaud por amplidão, buscada, no poeta francês, através de um desregramento dos sentidos que chegava a colocar em suspensão uma pensável unidade subjetiva. A idéia de uma unidade, freqüentemente ligada à personalidade do artista, é uma questão para muito da lírica moderna. É entre a unidade de uma personalidade e sua desintegração que me interessa investigar a experiência subjetiva em Dispersão.

\section{Abstract}

The poems of Dispersão, by Mário de Sá-Carneiro, show a singular poetics. There is, in the poems, a self that is the center of the discourse, a self that tries to expand itself. That resembles Rimbaud's desire for amplitude, sought after, by the French poet, through a dissipation of the senses that puts in suspension a possible subjective unity. The idea of unity, often connected to the artist's personality, is a question beyond modern lyric. My interest is to investigate the subjective experience in Dispersão, thinking about the unity of a personality and its dissipation. 